\title{
MODERNISTYCZNY BUDYNEK SZPITALA W NOWEJ SOLI. NIEZNANE DZIELO ERNSTA KOPPA. PRZYKLAD RACJONALIZACJI FUNKCJI, TECHNOLOGII, KONSTRUKCJI
}

\begin{abstract}
Nowa Sól jest stosunkowo młodym miastem. Mimo początków sięgających połowy $\mathrm{XV}$ w. prawa miejskie uzyskało dopiero w 1743 r. Jest tu niewiele zabytków wysokiej klasy. Jednym z nich jest modernistyczny budynek dawnego szpitala. Znaczenie tej budowli jest wyjątkowe, nie tylko ze względu na architekturę, ale także ze względu na jej twórcę, którym był niemiecki architekt Ernst Kopp (1890-1962). Obiekt zbudowany w Nowej Soli był jego pierwszym projektem, w którym zaproponował innowacyjne podejście do tego typu budownictwa. Takie kompaktowe i ekonomiczne szpitale wzniesiono, $\mathrm{z}$ drobnymi zmianami, także $\mathrm{w}$ innych niemieckich miastach, Gütersloh w 1932 r. i w Holzminden w 1933 r. Kolejna realizacja Koppa to wielopiętrowy szpital im. M. Lutra w Berlinie wzniesiony w 1931 r., który w momencie otwarcia został uznany za najbardziej nowoczesny obiekt w stolicy Niemiec. Kopp opracował koncepcję funkcjonalnego, ekonomicznego szpitala krótkich dystansów, która opierała się na zasadzie kwadratowego rzutu poziomego, eliminującego duże odległości, które w placówce musi pokonywać personel. Odnaleziony w Archiwum Państwowym w Zielonej Górze projekt szpitala w Nowej Soli pozwala na szczegółową analizę rozwiązań funkcjonalnych. W 2002 r. budynek został sprzedany prywatnemu przedsiębiorcy, który nie zakończył remontu. Obecnie niezabezpieczony budynek ulega powolnej dewastacji Jest to jedyna realizacja Ernsta Koppa na terenie Polski. Razem z otaczającym parkiem, dawny szpital stanowi istotny element kompozycyjny i architektoniczny modernistycznej części dzielnicy Zatorze w Nowej Soli.
\end{abstract}

Słowa kluczowe: architektura, modernizm, forma, funkcja, konstrukcja, szpital, zabytek

\section{Wprowadzenie}

Nowa Sól jest miastem, którego początki sięgają połowy XV w. Jego zalążkiem była warzelnia soli i skupione przy niej osiedle robotników. Dopiero w 1743 r. osada uzyskała prawa miejskie. Jest tu mało zabytkowych budowli

\footnotetext{
${ }^{1}$ Wojciech Eckert, Uniwersytet Zielonogórski, Wydział Budownictwa, Architektury i Inżynierii Środowiska, ul. Licealna 9, 65-417 Zielona Góra; tel. 6832824 16; w.eckert@ib.uz.zgora.pl
} 
o znaczących wartościach kulturowych. Jednym z nich jest nieznany szerzej, modernistyczny budynek dawnego szpitala.

Szpital jest zlokalizowany w południowo-zachodniej części miasta, w obrębie dzielnicy Zatorze. Znajduje się na dużej, zadrzewionej działce, zajmującej centralną część kwartału ograniczonego ulicami H. Sienkiewicza, Przyszłości, M. Skłodowskiej-Curie, K. Kaczkowskiego, Wojska Polskiego. Wzdłuż ulic usytuowana jest zabudowa jednorodzinna pochodząca z lat 20. i 30 . XX w. Główny wjazd na teren szpitala znajduje się od północnego zachodu, od strony ulicy H. Sienkiewicza.

\section{Historia}

Zatorze to dzielnica Nowej Soli, która powstała na początku XX w. na zachód od linii kolejowej. Jej plan zagospodarowania przestrzennego stworzył znany niemiecki architekt Peter Behrens. Ulica H. Sienkiewicza, niem. Raudener Strasse, miała stanowić główną oś dla dużego osiedla mieszkaniowego. Ostatecznie zmodyfikowany projekt realizowano od początku lat 20. XX w. W pierwszej kolejności przy ulicy H. Sienkiewicza wzniesiono budynki wielorodzinne, a od początku lat 30 . XX w. rozpoczęto budowę domów jednorodzinnych. [2]

Teren na zapleczu ulicy przeznaczono na budowę szpitala powiatowego. W 1927 r. powołano komitet budowy szpitala, a rok później powstał projekt budynku autorstwa architekta Ernsta Koppa. Kamień węgielny pod budowę szpitala położono 18 grudnia $1928 \mathrm{r}$. Inwestycję zrealizowano bardzo szybko, w pierwszym roku światowego kryzysu gospodarczego. Projekt ten otrzymał priorytet wśród wszystkich inwestycji prowadzonych na terenie ówczesnego powiatu kożuchowskiego oraz wsparcie rządowe. Uroczyste otwarcie miało miejsce 26 kwietnia $1930 \mathrm{r}$.

Twórca projektu - Ernst Kopp (1890-1962) zapisał się w historii architektury jako budowniczy nowoczesnych szpitali. Budynek w Nowej Soli był jego pierwszym projektem, w którym zrealizował innowacyjne podejście do budownictwa szpitalnego. Ten kompaktowy i ekonomiczny typ szpitala zrealizowano z drobnymi zmianami także w innych niemieckich miastach - w Gütersloh w 1932 r. oraz w Holzminden w 1933 r. Kolejne realizacje Koppa to wielopiętrowy szpital im. M. Lutra w Berlinie (1931 r.), który w momencie otwarcia uznano za najbardziej nowoczesny obiekt w stolicy Niemiec. Został on odtworzony w prawie niezmienionej formie w Aleksandrii w Egipcie. Za sprawą tych budynków Kopp zyskał międzynarodową sławę, a szpitale jego autorstwa odnaleźć można m.in. w Brazylii, Iranie, Pakistanie. [3]

Ernst Kopp postrzegał szpital jako złożony organizm, którego poszczególne organy powinny doskonale współgrać ze sobą. Opracował koncepcję funkcjonalnego, ekonomicznego szpitala krótkich dystansów. Opierała się ona na zasadzie kwadratowego rzutu poziomego, eliminującego duże odległości, które 
w placówce musi pokonywać personel. Oddziały zajmujące poszczególne piętra miały być samodzielne i połączone $\mathrm{z}$ centralnie położonymi pomieszczeniami zabiegowymi za pomocą windy. Istotną innowacją wprowadzoną przez Koppa było umiejscowienie kuchni na ostatniej kondygnacji. Dzięki temu zlikwidowano problemy $\mathrm{z}$ wentylacją i zapachami towarzyszącymi gotowaniu. Kuchnia centralna była połączona windą z kuchniami pomocniczymi, rozmieszczonymi na każdym piętrze. Do tzw. herbaciarni docierało jedzenie w większych pojemnikach z głównej kuchni i tu dopiero było porcjowane. [3]

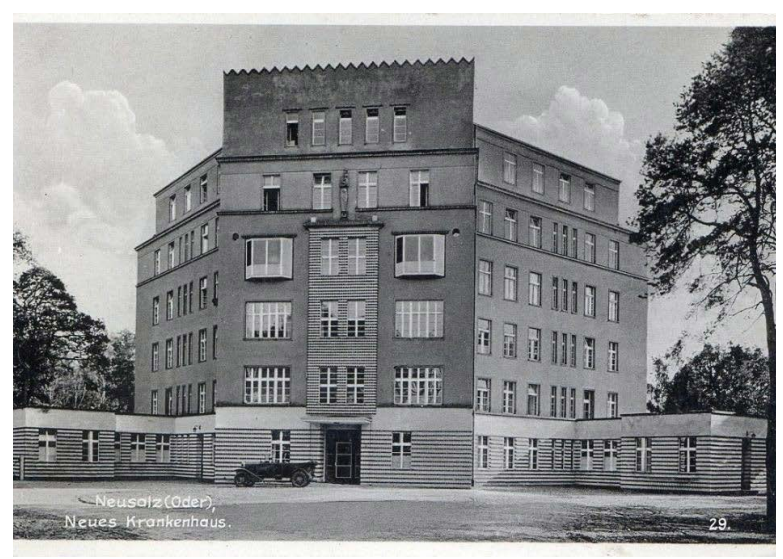

Rys. 1. Nowa Sól, szpital powiatowy, widok od północy. Pocztówka z 1. 30. XX w. [4]

Fig. 1. The district hospital building in Nowa Sól. The view from the North. Postcard dating from the 30's of the 20th century [4]

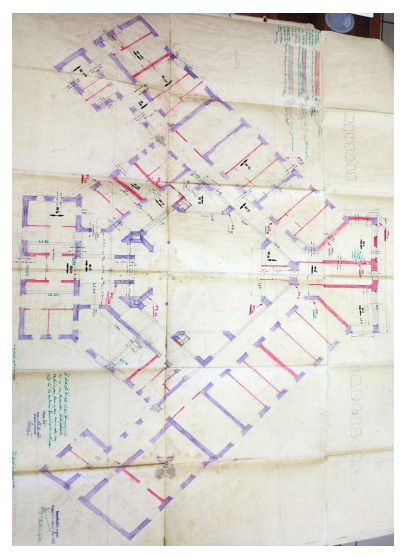

Rys. 2. Nowa Sól, szpital powiatowy, rzut parteru, projekt z $10.1928 \mathrm{r}$. [1]

Fig. 2. The district hospital building in Nowa Sól. Ground floor plan. The project of November 1928 [1]

Szpital w Nowej Soli był sześciokondygnacyjną budowlą centralną, założoną na rzucie sześciokąta $z$ wewnętrznym dziedzińcem. Elewacje o skromnym detalu architektonicznym były opracowane w cegle klinkierowej, jedynie szeroki pas tynku oddzielał poziom parteru od piętra. Szpital przeznaczony był na 135 tóżek. Okna sal chorych oraz świetlica wychodziły na słoneczną stronę południową, w kierunku parku. Po północnej stronie rozmieszczono głównie gabinety zabiegowe, pokoje administracyjne, magazyny. Na podstawie archiwalnych projektów i informacji zawartej w niemieckiej publikacji na temat Ernsta Koppa można opisać poszczególne kondygnacje. W piwnicy znajdowała się kotłownia i zaopatrzenie w ciepłą wodę oraz magazyny. Na parterze ulokowano biuro przyjęć, punkt pierwszej pomocy, oddział rentgenowski, izbę dziecięcą oraz oddział zakaźny, który posiadał osobne wejście i nie był połączony z pozostałą częścią budynku. Na pierwszym piętrze mieściły się gabinety lekarzy i ordynatora, laboratorium i sale na 28 łóżek. Na drugim piętrze funkcjonował oddział prywatny. Oddział chirurgiczny dla mężczyzn i strefę operacyjną zorganizowano na trzecim piętrze, a piętro czwarte było przeznaczone na oddział dla kobiet, 
w tym porodowy. Ostatnia kondygnacja była niepełna. W części północnej budynku urządzono kuchnię, a po południowej stronie mogły mieścić się otwarte tarasy. W pobliżu budynku głównego znajdowały się mniejsze obiekty przeznaczone dla karetek pogotowia, pralni i pomieszczeń dezynfekcyjnych. Wokół szpitala rozciągał się kilkuhektarowy park z ciągami spacerowymi, z sosnowym i brzozowym zagajnikiem oraz ogrodem warzywnym. Około 1940 r. w parku wybudowano cztery schrony przeciwlotnicze.

Po II wojnie światowej szpital został przejęty przez Armię Czerwoną i do 1991 r. funkcjonował jako Szpital Wojskowy Północnej Grupy Wojsk Radzieckich. Teren szpitala wraz z pobliskimi domami stanowił zamknięty obszar przeznaczony na potrzeby jednostki wojskowej. Po likwidacji garnizonu radzieckiego w Nowej Soli obiekt został przekazany władzom miejskim. Przez pewien czas budynek był dzierżawiony przez Towarzystwo Agentów Celnych i Spedytorów w Zielonej Górze, ale ostatecznie niezabezpieczony uległ dewastacji pod koniec lat 90. XX w. W 2002 r. dawny szpital został sprzedany prywatnemu przedsiębiorcy, który go wyremontował i uporządkował park. Nie znaleziono jednak nowej funkcji dla budynku. Obecnie pozostaje nieużytkowany i niezabezpieczony, demolowany popada $\mathrm{w}$ ruinę.

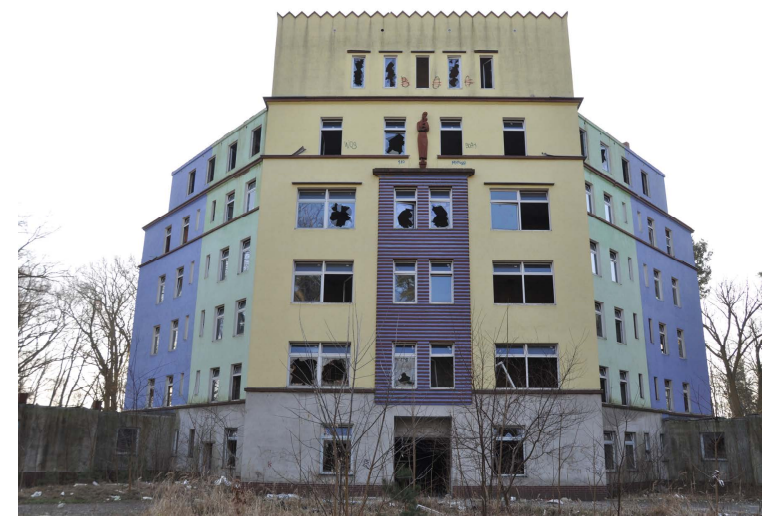

Rys. 3. Nowa Sól, dawny szpital powiatowy. Widok od północy na elewację frontową, stan obecny

Fig. 3. The building of the former district hospital in Nowa Sól. View from the North to the front elevation. Current state

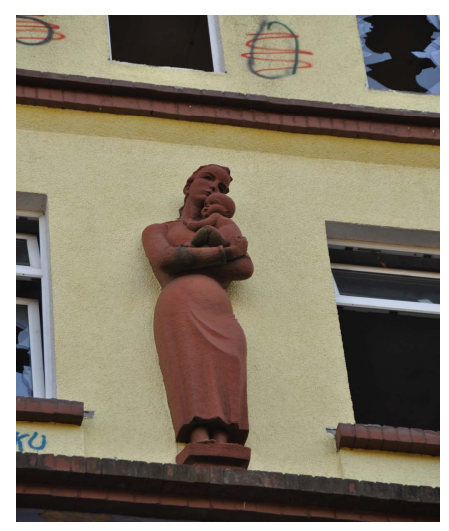

Rys. 4. Nowa Sól, dawny szpital powiatowy. Figura kobiety z dzieckiem na fasadzie

Fig. 4. The building of the former district hospital in Nowa Sól. Figure of a woman with a child, located on the facade

\section{Stan obecny budynku}

Jest to budowla centralna, założona na planie sześcioboku, z wewnętrznym dziedzińcem w kształcie ośmioboku, obecnie zadaszonym. Sześciokondygnacyjny, podpiwniczony korpus główny jest ujęty po bokach parterowymi skrzy- 
dłami. Ściany wzniesiono z cegły pełnej palonej na zaprawie cementowowapiennej, a pomieszczenia przekryto stropami ceramicznymi typu Ackermana. Wieloboczna bryła nakryta jest niskim dachem pulpitowym, odeskowanym, o pokryciu z papy. Elewacje były pierwotnie opracowane w cegle klinkierowej, obecnie są otynkowane. Posiadały skromny detal architektoniczny w formie gzymsów, opasek okiennych, portalu na elewacji tylnej. Oś centralna fasady oraz elewacji tylnej zostały podkreślone pseudoryzalitami, artykułowanymi poziomymi pasami ceglanymi i otynkowaną płaszczyzną pomiędzy nimi. Podobnie zostały opracowane elewacje skrzydeł bocznych. Obecnie te partie są również w całości otynkowane. Fasada została zamknięta attyką oraz ozdobiona pełnoplastyczną figurą kobiety $\mathrm{z}$ niemowlęciem $\mathrm{w}$ ramionach, która znajduje się na osi na poziomie piątej kondygnacji.

Układ wnętrza budynku odzwierciedlał nowatorskie idee architekta E. Koppa. Wejście główne z szerokimi drzwiami znajduje się na osi budynku. Poprzez wiatrołap prowadzi do przestronnego holu, na osi którego znajduje się szyb windy oraz żelbetowa, trójbiegowa klatka schodowa. Tylne wejście prowadzi do południowej części budynku, w której mieści się dwubiegowa żelbetowa klatka schodowa oraz szyb windy towarowej. Układ jest dwutraktowy - wewnętrzny to korytarz biegnący wokół patio, a zewnętrzny miał funkcję użytkową.

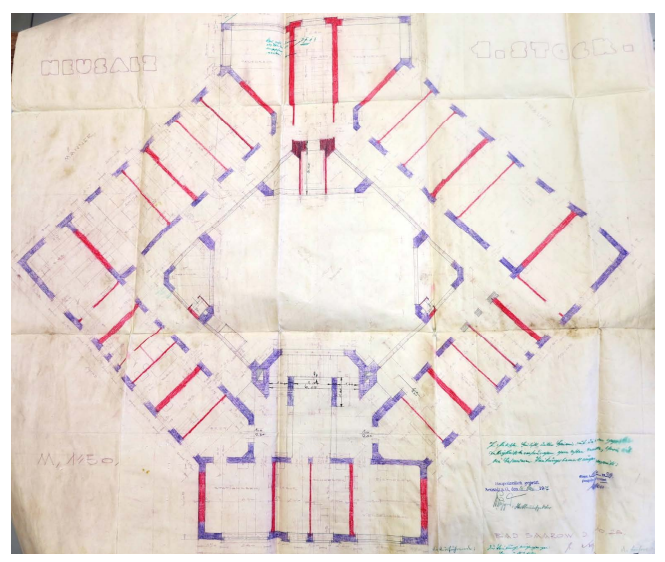

Rys. 5. Nowa Sól, szpital powiatowy, rzut parteru, projekt z 10.1928 r. [1]

Fig. 5. The district hospital building in Nowa Sól. First floor plan. The project of November 1928 [1]

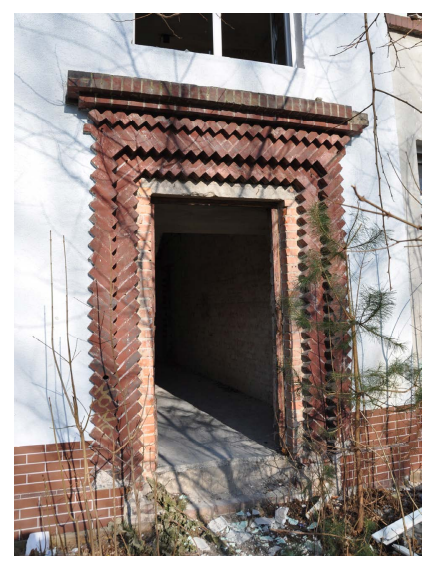

Rys. 6. Nowa Sól, dawny szpital powiatowy. Portal wejściowy w elewacji tylnej

Fig. 6. The building of the former district hospital in Nowa Sól. The entrance at the rear facade of the building

Rozpoczęty po 2002 r. remont generalny obiektu nie został ukończony. Największą wprowadzoną zmianą było zadaszenie dziedzińca, dzielące go na dodatkowe kondygnacje. Konstrukcję stanowią stalowe słupy i rygle, na których 
oparto gęstożebrowy strop żelbetowy. Ostatnią kondygnację przykryto stropodachem, składającym się z żelbetowego stropu i niskiego dachu pulpitowego, krytego papą. Istotną współczesną ingerencją był remont elewacji. Ściany zewnętrzne otynkowano, a poziom cokołu wyłożono okładziną ceramiczną. Z oryginalnego detalu zachowały się gzymsy kordonowe oraz portal na tylnej elewacji wykonane $\mathrm{z}$ cegły klinkierowej. Pozostawiono także rzeźbę kobiety z dzieckiem na fasadzie. Kształt okien - przede wszystkim na elewacji tylnej i częściowo na bocznych, został zmieniony. Część otworów zamurowano, wybito też nowe okna. Na fasadzie zlikwidowano wykusze na trzecim piętrze. We wszystkich otworach okiennych wymieniono stolarkę, która nie utrzymuje oryginalnych podziałów.

Nie zachował się oryginalny wystrój ani wyposażenie. Tynki wewnętrzne zostały skute. Pozostały ślady pierwotnej malatury sufitów w kolorze pomarańczowym na ostatniej kondygnacji. Niektóre ściany działowe wyburzono, postawiono kilka nowych. Część otworów okiennych i drzwiowych zamurowano. Zlikwidowano windy. Ściany najwyższej kondygnacji częściowo ocieplono od wewnątrz styropianem i bloczkami gazobetonowymi. Podłogi usunięto, na fragmentach zachowało się lastriko. Prace remontowe we wnętrzu zmieniły w niewielkim stopniu układ funkcjonalny budynku.

Pomimo współczesnych prac remontowych i modernizacyjnych budynek utrzymał oryginalną formę. Z wyjątkiem zadaszenia nad patio bryła zachowała się bez przekształceń. Obecnie budynek pozostaje niezabezpieczony, stając się obiektem wandalizmu.

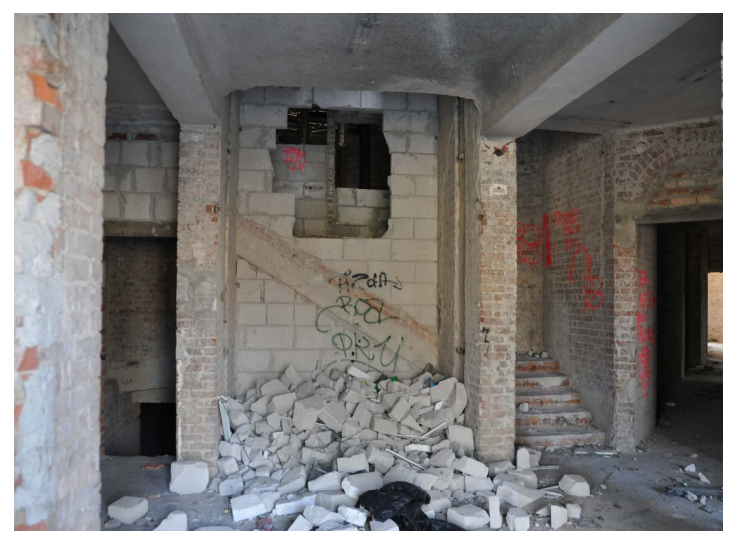

Rys. 7. Nowa Sól, dawny szpital powiatowy, hol przy wejściu głównym, stan obecny

Fig. 7. The building of the former district hospital in Nowa Sól. The lobby at the main entrance of the building

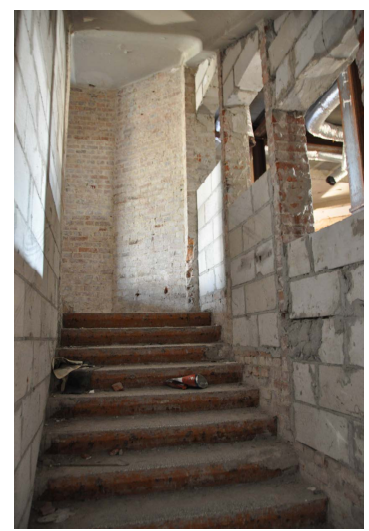

Rys. 8. Nowa Sól, dawny szpital powiatowy, klatka schodowa po stronie północnej

Fig. 8. The building of the former district hospital in Nowa Sól. The staircase of the building on the northern side 
W parku otaczającym szpital występują liczne okazy starych drzew, głownie okazałych sosen i dębów. Przed wejściem głównym widoczny jest kształt dawnego gazonu. Ciągi komunikacyjne nie są czytelne. Układ kompozycyjny wymaga prac rewaloryzacyjnych.

Budynek został wzniesiony w stylu modernistycznym, cechując się wyrazistą i kubiczną bryłą, zdyscyplinowanym użyciem detalu architektonicznego, klarowną kompozycją i układem wnętrz podporządkowanym idei optymalizacji i ekonomizacji.

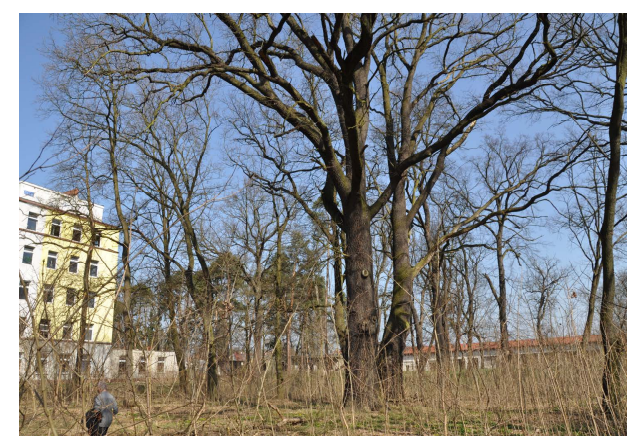

Rys. 9. Nowa Sól, dawny szpital powiatowy, pomnikowe drzewa na terenie parku

Fig. 9. The building of the former district hospital in Nowa Sol. The monumental trees in the spital park

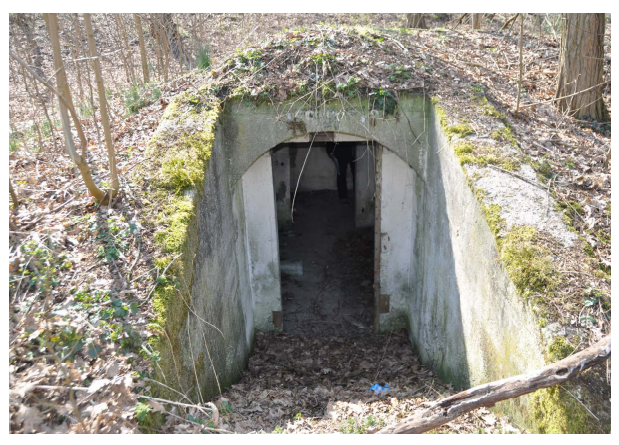

Rys. 10. Nowa Sól, dawny szpital powiatowy, schron na terenie parku

\section{Wnioski}

Budynek będący przedmiotem analizy to wyjątkowy przykład nowoczesnej architektury, reprezentujący styl modernistyczny. Jest to pierwszy wieżowiec szpitalny na terenie ówczesnych Niemiec i pierwszy projekt znanego architekta szpitali - Ernsta Koppa, w którym zrealizował nowatorskie rozwiązania. Jest to jedyna realizacja tego architekta na terenie Polski. Razem $\mathrm{z}$ otaczającym parkiem dawny szpital stanowi istotny element kompozycyjny i architektoniczny modernistycznej części dzielnicy Zatorze.

Niestety ten wyjątkowy obiekt, posiadający znaczące wartości zabytkowe, ulega powolnej, stopniowej degradacji, zarówno pod wpływem warunków atmosferycznych jak i dewastacji ze strony osób trzecich.

Istnieje pilna potrzeba wpisania modernistycznego budynku szpitala w Nowej Soli, wraz z jego otoczeniem, do rejestru zabytków. Umożliwi to przeprowadzenie przyszłego remontu pod nadzorem służb konserwatorskich tak aby można było wyeksponować piękno i oryginalność budowli zawarte nie tylko w jego architekturze i konstrukcji ale także wyjątkowych rozwiązaniach funkcjonalnych. 


\title{
Literatura
}

[1] Akta Miasta Nowa Sól, sygn. 1028-1033, w: Archiwum Państwowe w Zielonej Górze.

[2] T. Andrzejewski, M. Gącarzewicz, J. Parahus, Nowosolskie ulice, Tom 4, P-T, Nowa Sól 2011.

[3] P. R. Pawlik: Von Saarow nach Alexandria. Ernst Kopp (1890-1962).

[4] http://dolny-slask.org.pl \{dostęp 24. 02. 2015 r.\}.

\section{THE MODERNIST BUILDING OF THE HOSPITAL IN NOWA SÓL. UNKNOWN WORK OF ERNST KOPP. EXAMPLE OF EFFICIENCY OF FUNCTION, TECHNOLOGY AND CONSTRUCTION}

\begin{abstract}
S u m m a r y
Nowa Sól is a relatively young city. Although its origins dating back to the mid -15 th century, it was granted town privilages as late as in 1743 . There are few high class interesting sights here. One of them is the modernist building of the former hospital. The importance of this building is unique not only because of its architecture but also due to its creator, who was the German architect Ernst Kopp (1890-1962). The building, which was built in Nowa Sól was his first project, in which he proposed an innovative approach to such type of construction. Such compact and economical hospitals were built, with slight variations, also in other German cities - Gütersloh in 1932. and Holzminden in 1933. Another Kopp's realization is a multi-storey M. Luther Hospital in Berlin built in 1931, which at the time of opening was considered the most modern property in the capital of Germany. Kopp developed the concept of a functional, economical hospital of short distances, which was based on the principle of the square horizontal projection, eliminating long distances, that hospital staff had to walk. Found at the State Archives in Zielona Góra, the Nowa Sól hospital project allows for detailed analysis of functional solutions. In 2002 the building was sold to a private entrepreneur who did not complete the renovation. Currently unprotected, building of the former hospital is slowly being devastated. It is the only realization of Ernst Kopp in Poland. Along with the surrounding park, the old hospital is an important architectural and composition element of the modernist district of Zatorze in Nowa Sól.
\end{abstract}

Keywords: architecture, modernism, form, function, design, hospital, monument

Przestano do redakcji: 05.05.2016 $r$.

Przyjęto do druku: 15.12.2017 r. 